Revista do SELL

v. $4, n^{\circ} .2$

ISSN: $1983-3873$

\title{
RICARDO REIS, ALMA-TADEMA E HORÁCIO: UT PICTURA POESIS?
}

RICARDO REIS, ALMA-TADEMA AND HORATIUS: UT PICTURA POESIS?

Carlos Francisco de Morais

Universidade Federal do Triângulo Mineiro

RESUMO: O objetivo deste trabalho é investigar como dois artistas atuantes no período conhecido como Belle Époque, compreendido entre o final do século XIX e o início do século XX, estabeleciam, cada um a seu modo, um diálogo com um autor do período clássico, o poeta latino Quinto Horácio Flaco (65 a.C-8 a.C), de tal forma que se torna possível defender a hipótese de que ambos terminam por colocar as respectivas obras numa relação de proximidade, ainda que indireta. Os dois artistas mencionados são Ricardo Reis (1887-?), poeta heterônimo criado por Fernando Pessoa (1888-1935), e Sir Lawrence Alma-Tadema (1836-1912), pintor holandês que atuou principalmente na Inglaterra. Segundo o próprio Fernando Pessoa, como atesta um dos textos encontrados em seu espólio, Ricardo Reis era um "Horácio grego que escreve em português"; quanto a Alma-Tadema, o aproveitamento de formas e temas clássicos preside a escolha de procedimentos na parte mais significativa de sua produção pictórica; nela, a citação literal de poemas de Horácio é uma das marcas de seu estilo. Dessa forma, este estudo investigará como as referências a Horácio em Reis e Alma-Tadema se torna um nexo entre suas práticas poéticas, pictóricas e as concepções éticas e estéticas presentes nelas.

PALAVRAS-CHAVE: Fernando Pessoa; Ricardo Reis; Sir Lawrence Alma-Tadema; poesia; pintura.

ABSTRACT: This paper's objective is the study of how two artists of the Belle Époque established, each in his own way, a dialogue with the famous classic Latin poet Quintus Horatius Flaccus (65 BC-8BC), making possible the hypothesis that both put their respective works in a relation of proximity, even if in an indirect way. The two artists are Ricardo Reis (1887-?), heteronym poet created by Fernando Pesoa (1888-1935), and Sir Lawrence Alma-Tadema (1836-1912), a Dutch painter active mostly in England. According to Fernando Pessoa himself, Ricardo Reis was an Greek Horatius writing in Portuguese; in Alma-Tadema's paintings classic themes and shapes drive the choice of painting methods his more meaningfull parts, exemplified by the literal use of Horatius' verses in various works. Therefore, this paper will look into how the references to Horatius in Reis and Alma-Tadema becomes a nexus between their poetic and pictorial practices and their ethical and esthetical ideas.

KEYWORDS: Fernando Pessoa; Ricardo Reis; Sir Lawrence Alma-Tadema; poesia; pintura. 


\section{Revista do SELL}

v. $4, n^{\circ} .2$

ISSN: $1983-3873$

Em artigo resultante de apresentação de comunicação no III SELL - Simpósio Internacional de Estudos Linguísticos e Literários da UFTM, publicado sob o título "Fernando Pessoa e o Victorian Classicism: um diálogo possível" na Revista do SELL, edição de novembro de 2011, nossa proposta foi

examinar a possibilidade de um diálogo entre a obra poética heterônima de Fernando Pessoa e a produção pictórica dos integrantes do movimento conhecido como Victorian Classicism, que reuniu diversos artistas plásticos ingleses na passagem do século XIX para o XX. Em termos específicos, nos interessa investigar como a poesia de Ricardo Reis, o heterônimo pessoano de inspiração neoclássica, pode ser estudada paralelamente à pintura de Lord Frederick Leighton (1836-1890), Sir Lawrence Alma-Tadema, (1836-1932) e G. F. Watts (1817-1904), em termos de escolhas formais, temática e influências recebidas da antiguidade clássica. (MORAIS, 2011, p. 199).

No presente trabalho, nossa intenção é prosseguir nessa investigação, desta vez focalizando especificamente as relações que se pode observar sendo estabelecidas entre a poesia que Fernando Pessoa atribuiu a Ricardo Reis e a obra pictórica de Sir Lawrence Alma-Tadema, com base em dois nexos inerentes a ambas: seu contexto histórico de produção e as referências à lírica do poeta latino clássico Quinto Horácio Flaco (65 a.C-8 a.C).

Em seu já clássico estudo Literatura e sociedade, em capítulo no qual, a partir de múltiplos pontos de vista e referenciais teóricos, mas sempre com cuidado de miniaturista, temendo exagerar nas tintas com que pinta, Antonio Candido, ao investigar as relações que o texto literário estabelece com a sociedade em que é produzido, registra como mesmo os estudiosos cônscios de que, na análise literária, se deve dar a primazia à forma da obra e suas leis internas, não podem se furtar a examinar como tal texto dialoga com seu tempo e a sociedade em que tal forma se originou:

Frequentemente tendemos a considerar a obra literária como algo incondicionado, que existe em si e por si, agindo sobre nós graças a uma força própria que dispensa explicações. Esta idéia elementar repousa na hipótese de uma virtude criadora do escritor, misteriosamente pessoal; e, mesmo quando desfeita pela análise, permanece um pouco em todos nós, leitores, na medida em que significa repugnância do afeto às tentativas de definir os seus fatores, isto é, traçar de algum modo os seus limites.

Por isso, quando investigamos tais fatores e tentamos distingui-los, percebemos, na medida em que é possível, que os mais plenamente significativos são os internos, que costeiam as zonas indefiníveis da criação, além das quais, intacto e inabordável, persiste o mistério. Há todavia os externos, como aqueles de que se ocupará este artigo; secundários, não há dúvida, como explicação; dependendo de um ponto de vista mais 


\section{Revista do SELL}

v. $4, n^{\circ} .2$

ISSN: $1983-3873$

sociológico do que estético; mas necessários, senão à sondagem profunda das obras e dos criadores, pelo menos à compreensão das correntes, períodos, constantes estéticas. Um autor alemão chega a dizer, neste sentido, que mesmo considerando-se a priori metafísico o valor artístico, só de modo sociológico é possível elucidá-lo nas suas formas concretas particulares - pois nas sociedades civilizadas a criação é eminentemente relação entre grupos criadores e grupos receptores de vários tipos. Isto quer dizer que o escritor, numa determinada sociedade, é não apenas o indivíduo capaz de exprimir a sua originalidade (que o delimita e especifica entre todos), mas alguém desempenhando um papel social, ocupando uma posição relativa ao seu grupo profissional e correspondendo a certas expectativas dos leitores ou auditores. A matéria e a forma da sua obra dependerão em parte da tensão entre as veleidades profundas e a consonância ao meio, caracterizando um diálogo mais ou menos vivo entre criador e público. (CANDIDO, 2006, p. 83)

Essas reflexões são suscitadas pelo fato de nos servirem de base para responder a uma indagação que nos fizemos repetidas vezes: que condicionantes atuaram sobre Fernando Pessoa, nome máximo do Modernismo português, atuando sob o impacto da efervescência das vanguardas do início do século $X X$, a criar, entre a corte de seus heterônimos, um de perfil marcadamente clássico, à maneira da antiguidade grecoromana que Marinetti, em seu Manifesto Futurista, pretendia ser inferior à cultura que produzia automóveis último tipo, não Vitórias de Samotrácia?

Já são conhecidas as explicações sobre a gênese dos heterônimos dadas por Pessoa a Adolfo Casais Monteiro, na famosa carta de 13 de janeiro de 1935. No que tange a Ricardo Reis, o poeta recorda que

Aí por 1912, salvo erro (que nunca pode ser grande), veio-me à ideia escrever uns poemas de índole pagã. Esbocei umas coisas em verso irregular (não no estilo Álvaro de Campos, mas num estilo de meia regularidade), e abandonei o caso. Esboçara-se-me, contudo, numa penumbra mal urdida, um vago retrato da pessoa que estava a fazer aquilo. (Tinha nascido, sem que eu soubesse, o Ricardo Reis). (PESSOA, 1986, p. 199)

$\mathrm{Na}$ já vasta fortuna crítica dos heterônimos, da qual fazem parte numerosos textos assinados pelo próprio Pessoa ou os próprios heterônimos, essa é a referência que registra o surgimento de Reis com a data mais antiga.

A versão canônica (repetida mesmo na recentíssima biografia de Fernando Pessoa escrita por José Paulo Cavalcanti Filho, que logo trata de desmistificá-la), entretanto, é a que coloca Reis no âmbito do "triunfal" dia oito de março de 1914:

Ano e meio, ou dois anos depois, lembrei-me um dia de fazer uma partida ao Sá-Carneiro - de inventar um poeta bucólico, de espécie 


\section{Revista do SELL}

v. $4, n^{\circ} .2$

ISSN: $1983-3873$

complicada, e apresentar-lho, já me não lembro como, em qualquer espécie de realidade. Levei uns dias a elaborar o poeta mas nada consegui. Num dia em que finalmente desistira - foi em 8 de Março de 1914 - acerquei-me de uma cómoda alta, e, tomando um papel, comecei a escrever, de pé, como escrevo sempre que posso. E escrevi trinta e tantos poemas a fio, numa espécie de êxtase cuja natureza não conseguirei definir. Foi o dia triunfal da minha vida, e nunca poderei ter outro assim. Abri com um título, $O$ Guardador de Rebanhos. E o que se seguiu foi o aparecimento de alguém em mim, a quem dei desde logo o nome de Alberto Caeiro. Desculpe-me o absurdo da frase: aparecera em mim o meu mestre. Foi essa a sensação imediata que tive. $E$ tanto assim que, escritos que foram esses trinta e tantos poemas, imediatamente peguei noutro papel e escrevi, a fio, também, os seis poemas que constituem a Chuva Oblíqua, de Fernando Pessoa. Imediatamente e totalmente... Foi o regresso de Fernando Pessoa Alberto Caeiro a Fernando Pessoa ele só. Ou, melhor, foi a reacção de Fernando Pessoa contra a sua inexistência como Alberto Caeiro.

Aparecido Alberto Caeiro, tratei logo de Ihe descobrir - instintiva e subconscientemente - uns discípulos. Arranquei do seu falso paganismo o Ricardo Reis latente, descobri-lhe o nome, e ajustei-o a si mesmo, porque nessa altura já o via. E, de repente, e em derivação oposta à de Ricardo Reis, surgiu-me impetuosamente um novo indivíduo. Num jacto, e à máquina de escrever, sem interrupção nem emenda, surgiu a Ode Triunfal de Álvaro de Campos - a Ode com esse nome e o homem com o nome que tem. (PESSOA, 1985, p. 199)

Em seu artigo "Neoclassicismo nas odes de Ricardo Reis", Elêusis Camocardi aponta outra possibilidade de explicação para a criação de Reis por Pessoa, valendo-se de dados biográficos do poeta, de seu tempo de estudante na África do Sul; tal hipótese é secundada por Márcia Manir Feitosa, em seu livro sobre as relações intertextuais da poesia de Reis, em passagem que incorpora parte do estudo de Camocardi:

"De um vago moreno mate", mais forte e mais seco do que Caeiro, de constituição mais frágil e débil, Reis, de formação latinista e semihelenista, parece ter sido inspirado por Pessoa quando da permanência deste na África do Sul, na Durban High School. O estudo de Elêusis Mírian Camocardi acerca do neoclassicismo nas odes de Reis sustenta essa possibilidade de criação física e intelectual do heterônimo.

"Há muitas hipóteses de influências recebidas por Fernando Pessoa para 'inventar' o heterônimo neoclássico. A formação latinista e semihelenista de Ricardo Reis advém da influência escolar que, na Durban High School, Fernando Pessoa recebera de seu professor de Latim, Headmaster W. H. Nicholas, homem que deixara profundas marcas nos seus discípulos, 'pela sua marcante personalidade e conhecimento incomum, não só da sua matéria como de todos os assuntos adjacentes'. Caracterizado como um mestre apaixonadamente devotado ao latim e sem complacência com quem não se sobressaísse na sua disciplina, escrevera excellent ao lado do nome de Fernando Pessoa, como grau de aproveitamento nessa matéria. Também a caracterização física de Ricardo Reis parece ter sido decalcada sobre a figura de W. H. Nicholas que, 'tal como Ricardo Reis, era de um vago moreno mate"'. (FEITOSA, 1998, p. 150-151) 


\section{Revista do SELL}

v. $4, n^{\circ} .2$

ISSN: $1983-3873$

Nestas páginas, contudo, não nos interessa desenvolver nem a hipótese canônica, com seus ares mitológicos emprestados por Pessoa (trinta e tantos poemas numa só noite?), nem a biográfica. Como indica a utilização que fizemos do texto de Antonio Candido, nosso intento é explorar como o perfil neoclássico de Ricardo Reis pode resultar da imersão de Fernando Pessoa num ambiente cultural em que, entre as mais variadas vertentes, também encontrava seu lugar, e com destaque, a valorização da cultura clássica greco-latina.

O ambiente cultural ao qual nos referimos acima é o do tempo em que Fernando Pessoa nasceu, formou-se culturalmente, seja na escola, seja por suas leituras, escreveu e, a seu modo, interveio. Trata-se da passagem das últimas décadas do século XIX para as primeiras do XX. Em termos históricos, no contexto da cultura ocidental, convencionouse chamar a esse tempo de várias formas, mas uma delas se sobressai. Na Inglaterra, fala-se em Era Vitoriana ou Eduardiana; nos Estados Unidos, em "Gilded Age"; na França, o termo consagrado é "Belle Époque"; dada a penetração da cultura de língua francesa naqueles dias, esse é o termo mais amplamente usado nos meios culturais mesmo hoje, como comprova o recentemente lançado Dawn of the Belle Époque, da pesquisadora estadunidense Mary McAuliffe, sendo, por isso, o adotado neste trabalho.

De modo sucinto, podemos registrar a variada gama de alternativas culturais prevalecentes naqueles anos, entre as quais o neoclassicismo: Realismo, Simbolismo, Impressionismo, Decadentismo, "Gesamtkunstwerk", "Art Noveau", Cubismo, Atonalismo, "Arts and Crafts", Secessão, Expressionismo, movimentos artísticos tão variados em suas propostas como revelam as produções de nomes tão díspares como Emile Zola, Leo Tolstoy, Stephane Mallarmé, Odilon Redon, Edouard Manet, Claude Monet, Oscar Wilde, Richard Wagner,Emile Gallé, Pablo Picasso, Alban Berg, Arnold Schoenberg, William Morris, Gustav Klimt, Edvard Munch etc. Neste ambiente cultural tão preocupado com o novo e as revoluções culturais possibilitadas pelo apogeu da Revolução Industrial, ainda assim a lição clássica não foi esquecida, sendo, na verdade, uma alternativa entre outras, como registra Christopher Wood em Olympian dreamers, seu estudo definitivo sobre o Vitorianos Clássicos: "In an age so ecletic as the High Victorian, it is hardly surprising that for some artists, classical subjects represented only one among many possible sources of inspiration". (WOOD, 1983, p. 15) 


\section{Revista do SELL}

v. $4, n^{\circ} .2$

ISSN: $1983-3873$

Nem Fernando Pessoa nem a criação de Ricardo Reis estão alheios a esse panorama.

O poeta, em texto, provavelmente, de 1915 , identifica justamente o neoclassicismo entre outras correntes culturais daquele momento, registrando a já conhecida oposição entre o espírito clássico e o romântico:

Entre as tendências recentes do espírito crítico europeu há uma que acima de todas avulta quer pelo (. . ) como está espalhada, quer pela coesão inteira dos vários pontos que representam a essência da sua doutrina. Essa tendência - representada pelo movimento conservador em política - aflora na crítica literária sob a forma do chamado neoclassicismo,.

No nome da doutrina vai já a sua explicação. Ela inclui uma contraposição aos princípios românticos ou post- românticos considerados quer como literariamente falsos (Matthew Arnold), quer como a forma literária de princípios políticos dissolventes - dos princípios por que ostensivamente se regia a literatura pré-revolucionária. (PESSOA, 1966, p, 144)

Nesse contexto, avulta a importância da nota abaixo, em que Pessoa, como se o "dia triunfal" ainda não tivesse entrado em sua mitopoese, mais uma vez oferece uma explicação diferente para a criação de Reis, ligando-o, agora, ao contexto cultural em que o neoclassicismo era uma alternativa ao modernismo emergente:

Ricardo Reis — vida dele.

O Dr. Ricardo Reis nasceu dentro da minha alma no dia 29 de Janeiro de 1914, pelas 11 horas da noite. Eu estivera ouvindo no dia anterior uma discussão extensa sobre os excessos, especialmente de realização, da arte moderna. Segundo o meu processo de sentir as coisas sem as sentir, fui-me deixando ir na onda dessa reacção momentânea. Quando reparei em que estava pensando, vi que tinha erguido uma teoria neoclássica, e que a ia desenvolvendo. Achei-a bela e calculei interessante se a desenvolvesse segundo princípios que não adopto nem aceito. Ocorreu-me a ideia de a tornar um neoclassicismo "científico» [...] reagir contra duas correntes tanto contra o romantismo moderno, como contra o neoclassicismo à Maurras. [...] (PESSOA, 1986, p. 385)

O Maurras a quem Pessoa se refere é Charles Maurras (1868-1952), poeta, crítico e jornalista francês, uma das personalidades mais notórias do fin-de-siècle na França em razão de seu ativismo monarquista, católico e conservador, tendo sido ele o lançador do 


\section{Revista do SELL \\ v. $4, n^{\circ} .2$}

ISSN: $1983-3873$

movimento ultradireitista e antissemita conhecido com "Action française". Fazia parte da complexa base ideológica de Maurras um retorno a uma visão clássica da arte e da organização da sociedade, como aponta Molnar:

At this point we are at the heart of Maurrassian doctrine, at the farthest pole from Anglo-Saxon premises: a Mediterranean worldview in which Greeks and Latins commune. The State is a work of art (Aristotle balancing Plato in neverending tension), an orderly and just arrangement, built for permanence, an ideal. It is far, unbridgeably far, from pragmatic politics, the duel of lobbies, voting procedures, responses to polls, authorized flag-burning. The classical spirit is everywhere present in Maurrassian literature, even in his full name: Charles-Marie-Photius, the last-mentioned from the sixth-century Greek merchant-discoverer of Marseille, metropolis of the Midi, not far from Maurras's birthplace. (MOLNAR, 1999)

No texto de Pessoa acima citado, não há explicações para sua discordância em relação ao "neoclassicismo" de Maurras, mas, consultados outros, avulta seu desprezo intelectual pelo francês, de maneira geral, e sua avaliação negativa da apropriação da cultura clássica proposta pela Action Française em particular, como evidenciam dois excertos de sua prosa.

O primeiro faz parte de uma consideração mais ampla da decadência cultural e filosófica dos portugueses:

Que ideias gerais temos? As que vamos buscar ao estrangeiro. Nem as vamos buscar aos movimentos filosóficos profundos do estrangeiro; vamos buscá-las à superfície, ao jornalismo de ideias. E assim as ideias que adoptamos, sem alteração nem crítica, são ou velhas ou superficiais. Falamos a sério nas ideias políticas de León Blum ou de Edouard Herriot, nenhum dos quais teve alguma vez ideias - políticas ou outras - em sua vida. Falamos a sério em Bourget, Maurras [...].

Plagiamos o fascismo e o hitlerismo, plagiamos claramente, com a desvergonha da inconsciência, como a criança imita sem hesitar. Não reparamos que fascismo e hitlerismo, em sua essência, nada têm de novo, porventura nada de aproveitável, como ideias; o que não sabemos imitar, porque seria mais difícil, é a personalidade de Mussolini.

As ideias de Maurras, que qualquer raciocinador hábil desfaz sem dificuldade, se tiver a paciência de vencer 0 tédio quase insuportável de o ler, passam por leis da natureza, por tão indiscutíveis como, não direi já a teoria atómica, que tem elementos discutíveis, mas o coeficiente de dilatação do ferro, ou a lei de Boyle ou de Mariotte. (PESSOA, 1979, p. 8, grifos nossos.) 


\section{Revista do SELL}

v. $4, n^{\circ} .2$

ISSN: $1983-3873$

O segundo ataca justamente a base da aproximação de Maurras do classicismo, por retirar-lhe totalmente o sentido ao acusá-lo de romantismo, afinal, desde, ao menos, Victor Hugo, não se encontrarão românticos dispostos a se intitularem neoclássicos:

Maurras e os seus são os românticos da Disciplina. Interpretam a disciplina romanticamente. Aproveitam o catolicismo e o monarquismo como disciplinas - processo de puro romantismo; ao passo que um classicista aproveitaria da religião católica e da instituição monárquica apenas aquilo que conviesse à disciplina como disciplina, reparando sempre que essa disciplina tem de ser aplicada ao nosso tempo. (Mas eles arranjam um conceito abstracto de Disciplina). (PESSOA, 1990, p, 319, grifos nossos)

Se Pessoa via com derrisão o que se propunha como neoclassicismo em França, é de se supor que não o fizesse com o que era proposto sobre isso na Inglaterra, onde a lição clássica se fazia novamente valorizar com uma penetração incontestável, talvez proporcional à profundidade com se baseava nos autores antigos mais autorizados.

Na cultura inglesa, com a qual não se pode exagerar a força da ligação que Pessoa teve a vida inteira (sua formação escolar foi toda feita em inglês, na África do Sul; os primeiros livros que publicou foram todos de poemas escritos em inglês; a última frase que escreveu, já em seu leito de morte, foi "I know not what tomorrow will bring") ${ }^{1}$ já é consensual a noção de que, no fim de século que preparava as vanguardas, também os neoclássicos detinham considerável espaço de atuação. Descrever esse estado de coisas é justamente o propósito do livro Olympian dreamers, de Christopher Wood, em cuja introdução se lêem as seguintes palavras:

Since the Renaissance, every generation of European artists has sought to reinterpret the great events of classical history, and mythology, in the light of their own experience. The Victorians were no exceptions. Admiration for Greek and Roman achievements was part of the very fabric of Victorian culture. It permeates all aspects of Victorian life - not only the arts but also literature, philosophy, education, theatre, fashion, politics, empire, war, even religion. It is beyond the scope of this book to explore all these avenues of influence in detail, bur all of them impinged in some way on the Victorian classical movement, and on the lives and the attitudes of the artists who contributed to it. In painting, it produced a definite classical phase, beginning in the 1860s, as a reaction against the predominance of Ruskin and the Pre-Raphaelites, and continuing right up to the First World War. In this book, I have attempted to chart this classical movement, the Victorian Parnassus, by concentrating on the careers of the five artists who made the greatest contribution to it - Leighton, Watts, Alma-Tadema, Poynter and Waterhouse. Through these five very different, but Olympian figures, one can

\footnotetext{
${ }^{1}$ Sobre isso, veja-se nosso artigo "Fernando Pessoa e o Victorian Classicism: um diálogo possível” na Revista do SELL, edição de novembro de 2011.
} 


\section{Revista do SELL}

v. $4, n^{\circ} .2$

ISSN: $1983-3873$

see the very different ways in which the classical ideal influenced Victorian art over a period of fifty years. (WOOD, 1983, p. 15)

Um nexo entre a produção pictórica do Parnaso Vitoriano e a poética de Ricardo Reis, de tal modo que esta não possa ser entendida como um acidente fortuito da inspiração pessoana, mas como uma produção artistica que deve ser lida contra um pano de fundo mais amplo, pode ser visto no aproveitamento que, como ele, Sir Lawrence Alma-Tadema faz da poesia lírica de Horácio.

Em seu estudo sobre o pintor, Barrow descreve a penetração da influência horaciana sobre a cultura inglesa da era vitoriana e, em particular, sobre a pintura de Alma-Tadema, nestes termos:

In the same year that $A$ Dedication to Bacchus was shown at the Lefèvre Gallery, a very different but equally intriguing work, A Favourite Poet was exhibited at the New Gallery. Set in a sumptuous interior with a glimpse of sea through an open window, A Favourite Poet shows a woman reading from a papyrus roll to her reclining companion. As often, one woman has a dark complexion and the other is distinctly fair. Partly obscured behind the reclining figure, a bronze wall panel is inscribed with a short passage from the Roman poet, Horace. It is no surprise that the favourite poet here is Horace: he was perhaps the best-known of all ancient poets in nineteenthcentury England. Victorian classicist, W. Y. Sellar, wrote of the Odes, "scarcely any work in any literature has been so widely and so familiarly known", while for Andrew Lang, Horace was "of mortals the most human, the friend of my friends and of so many generations of men. Horace was also cited in the works of creative writers of the period. For example, the poet Ernest Dowson uses lines form the Odes as titles of two of his poems, while many more Horatian allusions are scattered throughout his works. AlmaTadema had already completed A Difficult Line from Horace (1881), a depiction of a man puzzling over a line of verse, which was even used as the frontspice for an edition of Horace's work.

For this painter of Roman life, Horace's Odes epitomize a lighthearted and carefree urbanity, often associated with some love interest, and played out at a luxurious Rome or a resort on the Bay of Naples. Indeed, even when no inscription or quotation cites a Horatian source, the mood, setting and subject are often sufficient to reveal it. In 1883 the critic of the Art Journal proclaimed of the men and women form Alma-Tadema's paintings: "We name [them] from the Odes of Horace". (BARROW, 2008, p. 140)

Já sobre a propriedade da ligação da poesia de Reis com a de Horácio, devem bastar estas palavras de Elisete E. Ferreira da Silva:

Ricardo Reis, por sua vez, busca Horácio como fonte de onde haurir a motivação a uma apropriação de temas e concepções estéticas do antigo lirismo clássico. Como afirma Jacinto do Prado Coelho (1973, p. 144-146), ao se referir às concepções que marcam a poética do heterônimo pessoano, 


\section{Revista do SELL}

v. $4, n^{\circ} .2$

ISSN: $1983-3873$

o classicismo de Reis possui um sentido histórico-literário que "consiste no tratamento de temas típicos da literatura greco-latina, alimentada por conceitos de vida pagãos de que Reis se apropriou, e ainda no recurso a processos versificatórios e lingüísticos que evocam a poesia horaciana ou a poesia neoclássica românica". Assim, pode-se concluir que a constada relação entre as poéticas de Horácio e de Ricardo Reis, expressões literárias estabelecidas em espaços temporais bastante distanciados, evidencia a potencialidade alcançada pelos discursos literários no sentido de incorporar em sua manifestação várias vozes, ao pronunciar aquilo que se propõe à primeira vista como unívoco. (SILVA, 2008, p. 1-2.)

O diálogo da obra pictórica de Sir Lawrence com a poética de Horácio pode ser atestado pelo exame da pintura aludida por Barrow na citação acima, ou seja, "A favourite poet", pintada em 1889, atualmente na Lady Lever Art Gallery, Port Sunlight, no Reino Unido, que reproduzimos abaixo:

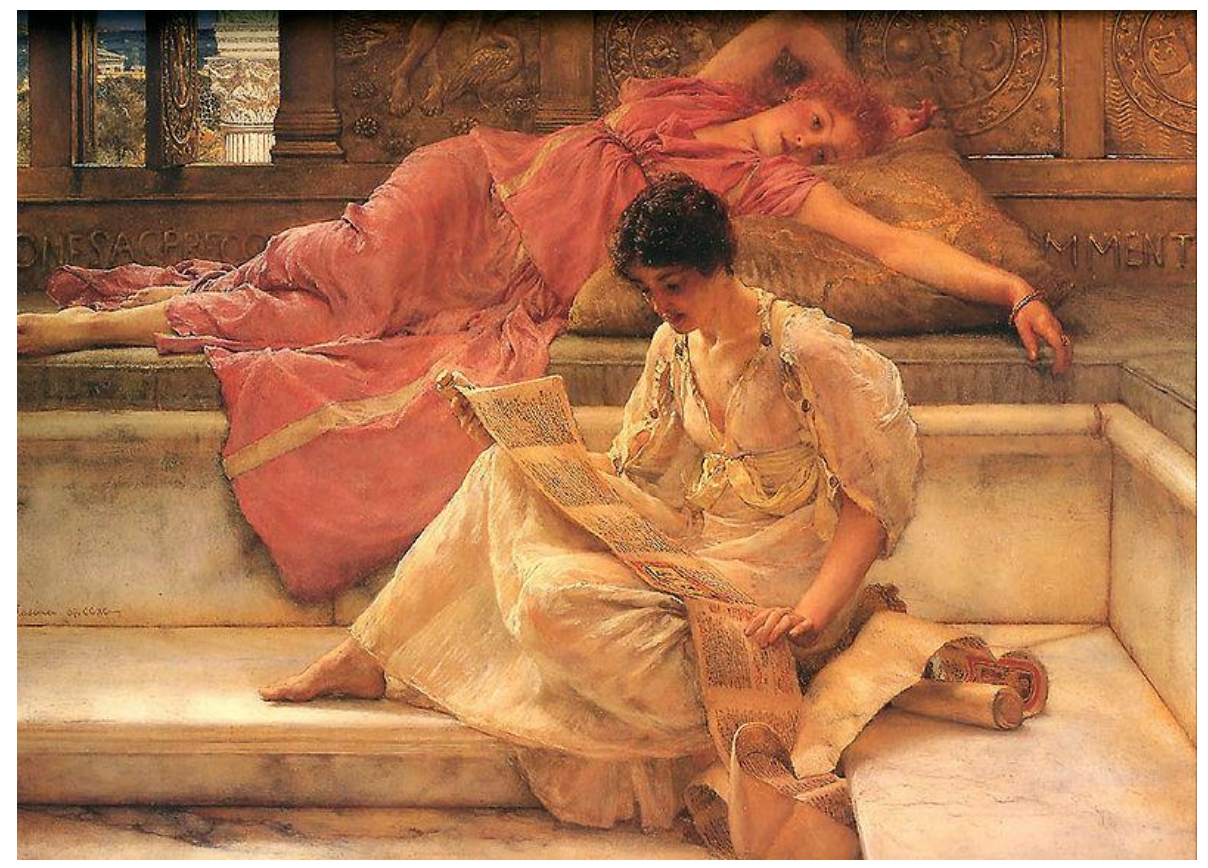

Esta imagem evidencia alguns elementos arquetípicos da pintura de Sir Lawrence, como a presença de mulheres jovens em poses lânguidas, vestidas à maneira das mulheres de classe elevada da Roma antiga, posicionadas em ambientes luxuosos e refinados, entregues a uma atividade em que a arte é elemento essencial; também é arquetípica a presença de elementos arquiteturais e o uso generoso do mármore na construção e na decoração das habitações. Repetem-se aqui também o contraste entre mulheres de cabelos escuros e claros e o das cores das vestimentas, assim como a 


\section{Revista do SELL}

v. $4, n^{\circ} .2$

ISSN: $1983-3873$

representação de detalhes de obras plásticas da antiguidade clássica e o uso de inscrições retiradas de textos dos grandes autores gregos e latinos. Com tudo isso, estamos a argumentar simplesmente que "A favourite poet" é uma pintura típica de AlmaTadema; o que a destaca entre as demais produções do pintor é apenas o altíssimo nível com que ele conseguir, aqui, realizar de maneira particular o que define seu estilo de maneira geral.

Quem é o poeta favorito do título do quadro? Seguindo a argumentação de Barrow, não há como não identificá-lo como Horácio, o que permite a interpretação da obra em termos que tornam possível a aproximação dela que dela fazemos com a poesia de Ricardo Reis, notadamente com a ode 53, iniciada pelo verso "Quero versos que sejam como joias". Conforme Barrow,

In the same year that $A$ Dedication to Bacchus was shown at the Lefèvre Gallery, a very different but equally intriguing work, A Favourite Poet was exhibited at the New Gallery. Set in a sumptuous interior with a glimpse of sea through an open window, A Favourite Poet shows a woman reading from a papyrus roll to her reclining companion. As often, one woman has a dark complexion and the other is distinctly fair. Partly obscured behind the reclining figure, a bronze wall panel is inscribed with a short passage from the Roman poet, Horace. It is no surprise that the favourite poet here is Horace: he was perhaps the best-known of all ancient poets in nineteenthcentury England. Victorian classicist, (BARROW, 2001, p. 140)

A inscrição no painel de bronze colocado atrás das moças reproduz os versos dezoito e dezenove da ode 31, do primeiro livro de Horácio: "Latoe, dones et, precor, integra/ cum mente, nec turpen senectam/ degere Nec cithara carentem". Em sua primorosa versão das odes e epodos de Horácio, Bento Prado de Almeida Ferraz assim os traduziu:

Dá-me, - eu te peço, - filho de Latona,

A mim, válido, forte, íntegra a mente,

Dá-me que frua da fortuna ganha

E velhice não sofra vergonhosa,

Nem me venha a faltar jamais a lira. (HORÁCIO, 2003, p. 77)

O filho de Latona, também conhecida como Leto, é Apolo, que ela concebeu, juntamente com Diana, de Júpiter. Apolo, como se sabe, recebe múltiplos atributos nas mitologias grega e romana, entre os quais se destacam os de deus da profecia e dos oráculos, da medicina, da poesia e da música, protetor dos jovens, pai de Orfeu. Não se pode, entretanto, negligenciar outro aspecto famoso de Apolo, segundo sua mitologia: os 


\section{Revista do SELL}

v. $4, n^{\circ} .2$

ISSN: $1983-3873$

seus diversos amores, impossíveis de compilar numa lista completa, da qual se destacam os episódios com deusas, semideusas e mortais, como Hécate, Héstia, Calíope, Urânia, Talia (divinas); Daphne, Leuconoe, Crisóstemes, Cirene, Melaina, Stilbe, Syllis (ninfas); Cassandra, Creusa, Marpessa, Hipermnestra (mulheres); Adônis, Jacinto (homens). A lembrança desse aspecto do deus não é fortuita quando se atenta para a citação em "A favourite poet" dos versos de Horácio que a ele aludem em perífrase, pois essa pintura reúne outros elementos ligados à expressão da sensualidade, de tal forma que o sentido geral da obra não pode ser alcançado sem a observação da atmosfera erótica nela criada.

Tal atmosfera já é indicada pela posição lânguida e lassa da moça vestida de tons avermelhados, o que só é enfatizado pelo rubor de suas faces. Por que ela enrubesce ao ouvir a leitura de uma ode de Horácio? Temos convicção de que a interpretação oferecida por Barrow tem valor, ao se apoiar no uso metafórico do instrumento musical mencionado nos versos:

The subject of the ode is the poet's prayer to Apollo on the occasion of Augustus' dedication of the temple of Apollo on the Palatine in 28 BC. Horace asks that he may not be without the lyre - that is, the "poetry" or joys of love - in his old age. The two beautiful women, one of whom is a reclining figure with flushed cheeks, point us to the erotic pleasures for which the poet hopes, and perhaps the women hope too. Furthermore, one of the wall panels shows the lower legs of a statue; cut-off at the knees and transformed from a marble sculpture to a bronze relief, it is still recognizable as a statue known as Pothos or desire. Textual inscription and archaeological detail here have no subversive significance, but instead a softly erotic mood is suggested in the form of the women, which is confirmed, as often, through erudite allusion. (BARROW, 2001, p. 140)

A leitura da ode completa certamente não desmente essas palavras:

Ode I, 31:

Que pede o vate ao celebrado Apolo?

Que pede, derramando do seu copo

Um vinho novo? Certo, não as férteis

Colheitas da Sardenha, ou os rebanhos

Soberbos da Calábria ardente, ou o ouro,

Ou o índico marfim, nem as campanhas

Que o Líris, taciturno rio de quietas

Águas, desgasta. Corte, à foice, a vinha

De Cales o feliz a quem fortuna

A deu; e o rico mercador enxugue

As taças áureas do adquirido vinho,

Por trocas feitas no mercado sírio,

Querido que é dos próprios deuses; pois,

Três vezes ou talvez quatro, cada ano, 


\section{Revista do SELL}

v. $4, n^{\circ} .2$

ISSN: $1983-3873$

O mar Atlântico visita impune.

A azeitona, a chicória ou a leve malva

São os meus alimentos prediletos.

Dá-me, - eu te peço, - filho de Latona,

A mim, válido, forte, íntegra a mente,

Dá-me que frua da fortuna ganha

E velhice não sofra vergonhosa,

Nem me venha a faltar jamais a lira. (HORÁCIO, 2003, p. 75-77)

É notável como, ao refletir sobre o que um poeta deve pedir ao deus da poesia, o eu-lírico faça uma lista de fontes de prazer, composta por repetidas referências ao vinho, mas também por outras ao ouro, ao marfim, aos produtos da fauna e da flora, às belezas naturais que, através das regiões italianas do Lácio, da Campânia e do Abruzzo, margeiam o rio Liri. Ao completá-la, entretanto, ele não passa diretamente a identificar o que pedirá a Apolo; antes disso, nos informa quais são seus maiores prazeres gastronômicos, que, certamente, em conjunção com os do vinho, poderiam rivalizar no gosto de um vate menos sábio: a azeitona, a chicória e a malva. Só depois de referir-se a elas é que o eu-lírico expressa seu pedido a Apolo, lavrado em termos que não deixam dúvidas sobre o papel da arte em sua vida, já que, para além da saúde física e mental e da fruição do dinheiro, pede que não Ihe falte nunca a lira. Ora, em texto tão conciso, não se poderá desprezar o fato de que os últimos prazeres nomeados antes desse prazer maior se refiram a alimentos tradicionalmente vistos como afrodisíacos, a chicória, a azeitona e a malva. Se esses atributos forem somados a perfeitamente pertinente interpretação que Barrows, com base no uso metonímico da lira, que nesta ode representa aquilo que ela simboliza desde a antiguidade, ou seja, a poesia (lírica) que fala do amor, estará mais que autorizada a visão de que nela o que mais se pede é a permanência do gozo erótico na velhice do poeta. Mais que o ouro, o marfim, o leite e o mel, Horácio valoriza nesta ode o amor, como era de se esperar de um poeta lírico.

É certamente para confirmar essa possibilidade de interpretação de "A favourite poet" num contexto de apologia do erotismo culto e refinado, mas ainda erotismo, e, sobretudo, para indicar a importância da lírica de Horácio como base para essa visão de mundo, que Sir Lawrence, como lembra Barrow, inclui em sua pintura, de maneira furtiva, mas não de todo, a reprodução de uma escultura famosíssima na antiguidade, cujo nome é Pothos, ou seja, desejo. O que falta na brilhante argumentação de Barrow sobre a utilidade dessa brincadeira estética de Sir Lawrence com os conhecedores de sua pintura, entretanto, é algo nada desprezível: o fato de que Pothos, obra realizada pelo escultor e arquiteto grego Scopas (c. 395 a.C-350 a.C) e conhecida pelo ocidente moderno por meio 


\section{Revista do SELL}

v. $4, n^{\circ} .2$

ISSN: $1983-3873$

de inúmeras cópias romanas, tem sido reconhecido como uma representação de Apolo, como é visível na cópia presente no Museu Capitolino, Roma, chamada de "Apollo Khitaroidos", ou seja, "Apolo tocador de lira". O quadro, então, está completo: a moça enrubesce ao ter diante de si a leitura de uma ode de Horácio em que o vate pede a Apolo o prazer erótico mesmo na vida provecta, sabedor que é de que não há vida sem prazer, como preconizava Epicuro; atrás dela, Apolo lembra o desejo e a figuração dele que cabe à poesia lírica fazer.

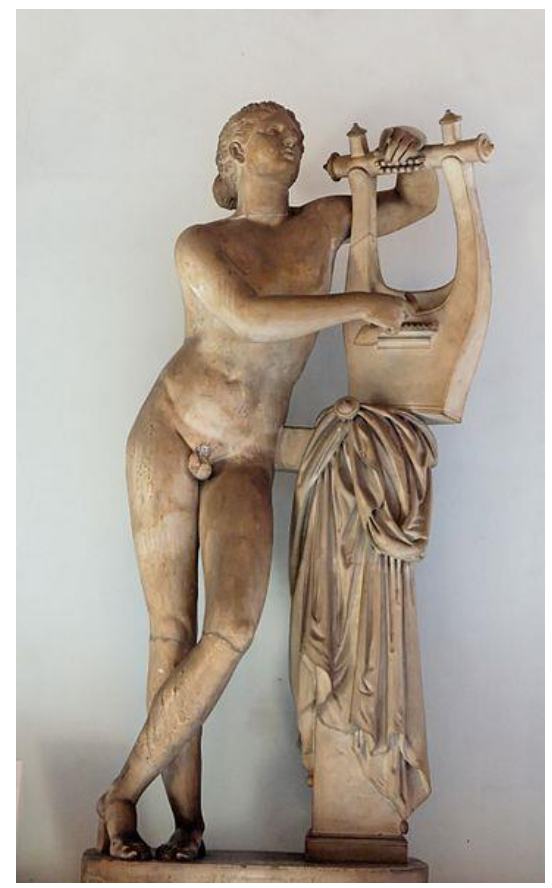

\section{APOLLO KHITAROIDOS}

É isso o que faz a ode 53 de Ricardo Reis, "Quero versos que sejam como joias", radicada na mesma ambientação cultural que presidiu à produção de "A favourite poet", centrada na lição estética e filosófica de Horácio.

Quero versos que sejam como jóias

Para que durem no porvir extenso

E os não macule a morte

Que em cada cousa a espreita,

Versos onde se esquece o duro e triste 


\section{Revista do SELL}

v. $4, n^{\circ} .2$

ISSN: $1983-3873$

Lapso curto dos dias e se volve

À antiga liberdade

Que talvez nunca houvemos.

Aqui, nestas amigas sombras postas

Longe, onde menos nos conhece a história

Lembro os que urdem, cuidados,

Seus descuidados versos.

E mais que a todos te lembrando, escrevo

Sob o vedado sol, e, te lembrando,

Bebo, imortal Horácio,

Supérfluo, à tua glória... (PESSOA, 2000, p. 85)

A ode 53 começa por ser a expressão de um desejo: a primeira palavra que nela lemos é o verbo "querer"; estando ele na $1^{\text {a }}$ Pessoa do Singular, já estabelece a pessoalidade, ou subjetividade, do desejo que preside a construção dos versos, os quais, aliás, falam de versos. O caráter metalinguístico da ode, assim, a aproxima de "A favourite poet", pois também essa pintura fala da poesia. Ut pictura poesis? Num poema composto por 88 palavras, há apenas mais três na mesma condição de verbos na primeira pessoa, o que não pode deixar de ser destacado; todas, "lembro", "escrevo" e "bebo", juntamente com "Quero", colocam a ode no âmbito epicurista da poética de Horácio, em que lira e vinho, vencendo o tempo, se irmanam, como vimos, na filosofia do bem viver baseado na permanência do desejo de prazer.

Sobre a primazia do prazer na filosofia de Epicuro (341 a.C-270 a.C) , seu registro mais autorizado está já na Carta a Meneceu:

"nós dizemos que o prazer é o princípio e o fim da vida feliz. É ele que antes de tudo aprendemos a reconhecer como um bem primeiro e congenital; depois, é por causa e em vista dele que orientamos as nossas escolhas e as nossas recusas, a ponto de fazermos das sensações de prazer cânones para o ajuizamento de tudo o que é bom" (EPICURO, 1997, p. 129)

Redolentes dessa filosofia, os versos de Ricardo Reis sobre os versos que deseja o eu-lírico em sua ode expressam a busca da beleza, da permanência e da pureza, como 


\section{Revista do SELL \\ v. $4, n^{\circ} .2$ \\ ISSN: $1983-3873$}

manifesta sua comparação com joias duradouras, capazes de superar o limite imposto ao homem, quer dizer, a morte, vista na ode como uma mácula que não atingirá os versos que sejam lapidados como o eterno diamante.

Em "Quero versos que sejam como joias", a poesia, e por extensão, a arte, assume poderes que só a ela competem, entre todas as atividades humanas, na poética de Reis. Assim é que esses atributos superiores da arte, em "Versos onde se esquece o duro e triste/Lapso curto dos dias" se materializam na capacidade de que tais versos desfrutam, a de oferecer a poetas e leitores o apagamento da única dimensão da vida humana a que não se pode fugir, o tempo. Suspenso de sua leitura ou audição, o leitor ideal desta ode também suspenderá a própria passagem das eras, mantendo a juventude prazerosa que nos Campos Elísios só os eleitos podem gozar. Assim, poderá, em plena vigência das vanguardas modernistas ou, mesmo, nos correntes dias, atualizar antigos ditos latinos, como "Ars longa vita brevis", tradução de Sêneca para aforismo em grego de Hipócrates, e o horaciano "Carpe diem".

"Quero versos que sejam como jóias" tem dezesseis versos; em seu verso central "Aqui, nestas amigas sombras postas", há muito mais do que a sutil descrição do lócus amoenus em que se desenrola o lirismo neoclássico de Reis. Atentando para a forma do verso, percebemos nele cinco palavras, o que permite, com facilidade, constatar qual é a palavra central dele e, por extensão, de toda a ode: "amigas". Não basta observar que tal palavra contamina a atividade que está sendo exercida sob as sombras que ela qualifica; é preciso reconhecer que também aqui se manifesta a busca pela felicidade, ou seja, do prazer, que coloca a ode sob a égide do pensamento epicurista, fonte inesgotável de inspiração para Horácio, acentuando o diálogo da lírica de Reis com a pintura de AlmaTadema. Isso ocorre por ser a amizade, na ética de Epicuro, uma promessa de felicidade, como diz um de seus aforismos: Das coisas que a sabedoria proporciona para tornar a vida inteiramente feliz, a maior de todas é uma amizade. Por sua posição central no texto, a amizade chama a atenção do leitor para o fato de que os desejos expressos nele se encaminham todos para a construção de uma mundividência calcada na fruição da vida como algo superior aos constrangimentos mundanos e diários, dedicada ao cultivo de valores livres das amarras do tempo: essa vida, na ode, só é dada pelos versos, pela arte, assim como a vida hedonista retratada em "A favourite poet" é cercada de arte por todos 


\section{Revista do SELL}

v. $4, n^{\circ} .2$

ISSN: $1983-3873$

os lados: das menores, como decoração, vestuário, ourivesaria, maquiagem, penteados, às maiores, como poesia, arquitetura e escultura.

A apologia do prazer como meio de vida é afirmada com mais evidência ainda nos últimos versos da ode 53, nos quais poesia e vinho se dão as mãos num brinde a Horácio: "E mais que a todos te lembrando, escrevo/ Sob o vedado sol, e, te lembrando,/ Bebo, imortal Horácio,/ Supérfluo, à tua glória..." Aqui, o eu-lírico registra como o prazer da vinho e o da escrita estão associados em sua prática, de tal forma que o erotismo não possa estar distante. Beber à memória de Horácio é beber em honra do "Carpe diem", das paisagens da Campânia, das águas do Liri, das taças áureas do vinho da Síria, das colheitas da Sardenha, da chicória, da azeitona e da malva, de Neera, Cloé e Lídia, musas horacianas tomadas de empréstimo pelo próprio Reis. É, em outras palavras, beber em honra da libido, entendida etimologicamente como "vontade", "anseio", "desejo", afinal.

É por essas aproximações filosóficas e estéticas que se pode depreender que Reis e Alma-Tadema fazem arte não só contemporaneamente, mas contra um pano de fundo cultural idêntico, ou seja, a pertinência da cultura clássica greco-latina mesmo no contexto de emergência dos modernismos, pertinência essa manifestada pela atualidade de Horácio no campo cultural em que tanto os Victorian Classics quanto Fernando Pessoa se formaram e atuavam. Se essas considerações nos permitem esta latitude, terminamos por dizer que, não fosse óbvio que as moças de Alma-Tadema estão saboreando a poesia de Horácio, poderíamos criar a hipótese de que enrubescem à melodia do Ricardo Reis, esse "Horácio grego que escreve em português", como já o descreveu o próprio Pessoa.

\section{REFERÊNCIAS}

BARROW, R. J. Lawrence Alma-Tadema. Londres: Phaidon, 2001.

CANDIDO, Antonio. Literatura e sociedade. $9^{\mathrm{a}}$ ed. rev. Rio de Janeiro: Ouro sobre azul, 2006.

EPICURO. Carta a Meneceu. Texto bilíngüe. Tradução de Álvaro Lorencini e Enzo del Carratore. São Paulo: Unesp, 1997. Apud SPINELLI, Miguel. "O conceito epicurista de 


\section{Revista do SELL}

v. $4, n^{\circ} .2$

ISSN: $1983-3873$

kritêrion vinculado ao de enargeías e de kanôn." In: Kriterion, Belo Horizonte, v. 53, n. 125, Junho $2012 . \quad$ Disponível em: <http://www.scielo.br/scielo.php?script=sci_arttext\&pid=S0100512X2012000100004\&lng=en\&nrm=iso >. Acesso em 18.10.2013.

FEITOSA, Márcia M. M. Fernando Pessoa e Omar Khayyam: o ruba'iyat na poesia portuguesa do século XX. São Paulo: Giordano, 1998.

HORÁCIO. Odes e epodos. Trad. Bento Prado de Almeida Ferraz. São Paulo: Martins Fontes, 2003.

McAULIFFE, Mary. Dawn of the Belle Epoque. The Paris of Monet, Zola, Bernhardt, Eiffel, Debussy, Clemenceau and their friends. Lanham/Md.: Rowman \& Littlefield, 2011.

MOLNAR, Thomas. "Charles Maurras, Shaper of an Age". In: First Principles Journal. Wilmington, Delaware: Intercollegiate Studies Institute, MA 41:4, Fall 1999. Disponivel em: http://www.firstprinciplesjournal.com/articles.aspx?loc=ja\&article=814. Acesso em 20.10.2013.

MORAIS, Carlos Francisco de. "Fernando Pessoa e o Victorian Classicism: um diálogo possível". In: Revista do SELL. Uberaba: UFTM, 2011, volume III, número II, p. 199-209.

PESSOA, Fernando. Ricardo Reis. Poesia. Org. Manuela Parreira da Silva. São Paulo: Companhia das Letras, 2000.

Escritos Íntimos, Cartas e Páginas Autobiográficas. (Introdução, organização e notas de António Quadros.) Lisboa: Publ. Europa-América,1986. Disponível em: http://arquivopessoa.net/typographia/textos/arquivopessoa-3007.pdf. Acesso em 20.10.2013.

Páginas de Estética e de Teoria Literárias. (Textos estabelecidos e prefaciados por Georg Rudolf Lind e Jacinto do Prado Coelho.) Lisboa: Ática, 1966. Disponível em http://arquivopessoa.net/typographia/textos/arquivopessoa-3774.pdf. Acesso em 20.10.2013.

Sobre Portugal - Introdução ao Problema Nacional. (Recolha de textos de Maria Isabel Rocheta e Maria Paula Morão. Introdução organizada por Joel Serrão.) Lisboa: Ática, 1979. Disponível em: http://arquivopessoa.net/textos/3506 . Acesso em 20.10.2013. 


\section{Revista do SELL}

v. $4, n^{\circ} .2$

ISSN: $1983-3873$

_ Pessoa por Conhecer - Textos para um Novo Mapa . (org. Teresa Rita Lopes.)

Lisboa: Estampa, 1990. Disponível em: http://arquivopessoa.net/textos/2686. Acesso em 20.10.2013.

SILVA, E. E. F. "Projeções do antigo: Horácio e Ricardo Reis". In: Tese (Belo Horizonte), v. $12, \quad$ p. $2008.15, \quad$ Disponível em: http://www.letras.ufmg.br/poslit/08 publicacoes pgs/Em\%20Tese\%2012/Proje\%C3\%A7\% C3\%B5es\%20do\%20antigo.pdf. Acesso em 20.10.2013.

WOOD, Christopher. Olympian dreamers. Victorian classical painters. 1860-1914. Londres: Constable, 1983. 